\title{
Investigation of Misalignment Affects During Creep Testing on the Miniature Pin-Loaded and the Sup-Size Uniaxial Creep Tests Specimens
}

\author{
Balhassn Ali \\ College of Petroleum Engineering, Al-Jafra University, Zalla, Libya \\ Email address: \\ blslma@yahoo.com, Balhassn.ali@ju.edu.ly

\section{To cite this article:} \\ Balhassn Ali. Investigation of Misalignment Affects During Creep Testing on the Miniature Pin-Loaded and the Sup-Size Uniaxial Creep \\ Tests Specimens. American Journal of Mechanical and Materials Engineering. Vol. 4, No. 2, 2020, pp. 37-42. \\ doi: 10.11648/j.ajmme.20200402.13
}

Received: May 16, 2020; Accepted: May 29, 2020; Published: June 16, 2020

\begin{abstract}
Creep is one of the main engineering problems facing engineers dealing with high temperature components. These components have to be closely monitored, especially after serving $50 \%$ of their residual life. For many reason creep engineers has to use small material samples for creep assessments of these components. Many small creep test specimen types can be manufactured using these small material samples; this include the sup-size uniaxial creep test specimen and the pin loaded small creep test specimen. Considering the limitations and the difficulties associated with each testing method is another factor often taken in to account before choosing which specimen type can be used. Traditionally many of creep engineers tend to go for the sup-size uniaxial creep test specimen, because of it is similarity to the standard creep test specimen. However, this specimen type has some limitations; this is include the high possibility of misalignment during the loading application, and this is due to the small size of the specimen. The misalignment effect on the test results normally ignored which can lead to inaccurate results. This paper will be focusing on the misalignment effect on the sup-size uniaxial creep test specimen, and the one-bar and two-bar creep test specimens. Using different values of misalignment the creep results obtained from one-bar and two-bar specimens and the sup-size uniaxial creep test specimen will be compared. The $\mathrm{P} 91$ steel at $650^{\circ} \mathrm{C}$, which is one of the high temperature materials, will be used for validation.
\end{abstract}

Keywords: Pin-Loaded Creep Test Specimen, OBS, TBS, Sup-Size Uniaxial Specimens, FEA Creep Analyses, Misalignments During Creep Testing Loading

\section{Interdiction}

Creep failure is one of the main problems facing most of the aged conventional power generation plants, Oil refineries and other industries, where the elevated temperature and the high stress levels are the norm in their daily operation $[1,2]$. Therefore, creep assessment of the old high temperature components become vital part in any maintenance and evaluation plan $[3,4]$. The operating company of those conventional power generation plants and Oil refineries are always seeking new methods to assess their plants high temperature components creep strength accurately and efficiently; in order for them to be able to renew their operating license from their local government or the responsible agency $[5,6]$.
The most common way of determining creep strength of any material, is by manufacturing a conventional cylindrical uniaxial creep test specimens from this particular material, with approximately a gage-length of about $100 \mathrm{~mm}$ and diameter of about $10 \mathrm{~mm}$. This specimen than should be tested by applying a tensile loading to both ends under elevated temperature, typically about $\% 30$ of the materials milting point, until the rupture of the specimen. Normally the outcome of this test is displayed as displacement-time curve or strain-time curve. These kind of curves than can be used as bases to determine the material creep strength. However, in many situations the conventional power generation plants operating companies and the Oil refineries operating companies find themselves in a position, where it is not possible for them to manufacture the conventional cylindrical 
uniaxial creep test specimens out from the tested high temperature component without compromising the component integrity. For this reason the small specimens creep testing techniques has been invented and used to test the high temperature components, and to estimate the remaining lifetime of these components $[2,3]$.

Small specimens creep testing [7-16] become inevitable method of assessing the creep strength of the high temperature components. The small specimens creep testing requires the removal of small material samples from the tested components. These small material samples are used to manufacture the small specimens for creep testing [13]. The results obtained from these small specimens is used to assess the creep strength and the remaining life of these critical components. Some of the small creep test specimens are loaded by applying a tensile loading to the specimens such as (i) the sup-size uniaxial specimen $[13,14]$ and (ii) the small two-bar specimen (TBS) [10] and (iii) the small one-bar specimen (OBS) [7, 8]. Some other testing techniques do not require applying tensile loading to the specimens such as the indention creep test [17] and the small punch creep test [18]. Any misalignment during loading may affect the specimen deformation and failure time. This paper has a numerical investigation using the finite element analyses, to assess the effects of the misalignment during loading on creep deformation and failure using the pin-loaded small specimens (OBS and TBS) and the sup-size uniaxial creep tests specimens.

\section{The Sup-Size Uniaxial Creep Test Specimen}

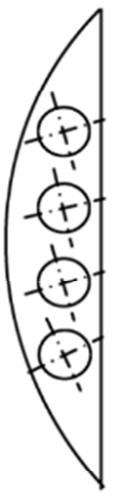

(a)

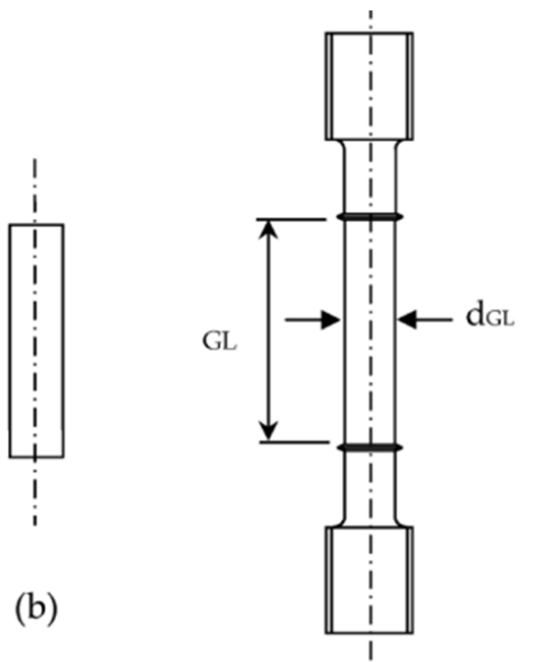

(c)
Figure 1. Positions of small cylindrical specimens in scoop samples (a), cylindrical specimens (b) and the sub-size creep test specimen (c).

This type of specimen can be manufactured from small material sample removed from a components surface such as a Headers in the power plant. For many years the sub-size creep test specimen shown in Figure 1, is used to assess the creep strength when there is limitation of the material available for creep testing. The specimen deformation and failure is very similar to the standard uniaxial creep test specimen deformation and failure. The specimen has small cylindrical bar which is relatively small, with gauge length about $(5-12 \mathrm{~mm})$ and gauge diameter about $(1-3 \mathrm{~mm})$. These mall dimensions allow the specimen to be constructed from very small material samples. Loading the specimen is the critical part in this testing technique, as the specimen has relatively small gauge length, a small conventional end pieces have to be attached (welded) to the specimen ends for loading purposes [14]. However, welding the two loading ends in the right position with good alignment achieved, is not an easy task and requires a complicated welding machine.

\section{The Small Pin-Loaded Creep Test Specimens Types}

\subsection{Small Two Bar Specimen (TBS)}

The pin-loaded, small two bar specimen (TBS) type [9, 10, 13], which is shown in Figure 2 and Figure 3, has a simple dimensions and geometry. The specimen dimensions are defined by $\mathrm{L}_{\mathrm{o}}, \mathrm{b}, \mathrm{d}, \mathrm{D}_{\mathrm{i}}$, and $\mathrm{k}$; where $\mathrm{L}_{\mathrm{o}}$ is the uniform "bar" length, i.e. the distance between the centres of the loading pins $\sim(5-13) \mathrm{mm}, \mathrm{b}$ is the bar width, $\mathrm{d}$ is the specimen thickness $\sim(1-2) \mathrm{mm}, \mathrm{b}$ is the uniform "bar" height $\sim(1-2)$ $\mathrm{mm}, \mathrm{D}_{\mathrm{i}}$ is the diameter of the loading pins $\sim(1-2.5) \mathrm{mm}$ and $\mathrm{k}$ is the length of the loading pin supporting end (4-7) $\mathrm{mm}$. The specimen is loaded under high temperature using two loading pins, one is to constrain the specimen and the other one is to apply the tensile load to the specimen. The specimen deformation is recorded throughout the test until the rupture of the specimen. Conversion relationships are used to convert the specimen deformation and the applied load to the corresponding uniaxial stress and strain $[13,14]$. The small TBS is capable of obtaining the creep strain and the creep rupture data [13].

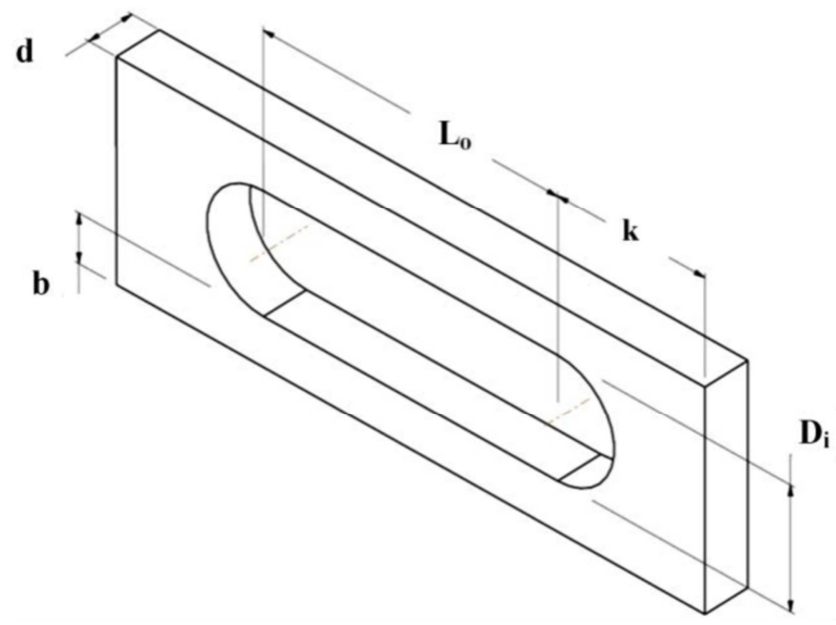

Figure 2. The two bar specimen (TBS) geometry and dimensions [10]. 


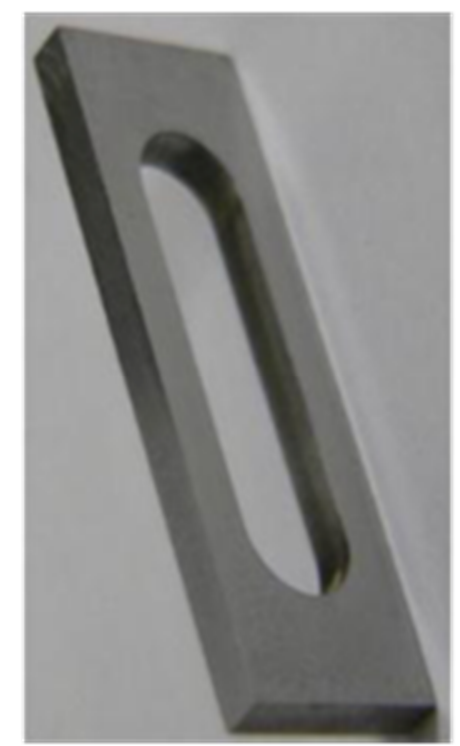

Figure 3. A photos of the small Two-bar specimen.

\subsection{The Pin-Loaded Small One-Bar Specimen (OBS)}

The pin-loaded small one-bar specimen is loaded using four loading pins (OBS), is recently developed and used to obtain full creep strain-time curves, using small material samples $[7,8]$. The OBS shape and dimensions are simple (see Figure 4), therefore can be easily manufactured, for example, using electrical discharge machine. The specimen dimensions are given by $\mathrm{L}_{\mathrm{o}}, \mathrm{k}, \mathrm{R}, \mathrm{b}$ and $\mathrm{d}$, where $\mathrm{L}_{\mathrm{o}}$ is the distance between the centres of the loading and concentrating pins $\sim(5-13) \mathrm{mm}, \mathrm{K}$ is the supporting material behind the loading pins $\sim(2-4) \mathrm{mm}, \mathrm{R}$ is the loading pin radius $\sim(1-2.5) \mathrm{mm}, \mathrm{b}$ is the bar thickness $\sim(1-2) \mathrm{mm}$ and $\mathrm{d}$ is the specimen depth $\sim(1-2) \mathrm{mm}$. The specimen is loaded using four loading pins, two are used to constrain the specimen and the other two are used to apply a tensile loaded to the specimen under elevated temperature. The loading pins can be attached to the loading machine using flexible joint, in order to allow good alignment to be achieved during the loading application [7]. The specimen deformation (the loading pins displacement) is recorded throughout the test until the rupture of the specimen. The small OBS is capable of obtaining the creep strain and creep rupture data $[7,8]$. The main differences between the OBS and the TBS are:

(i). the OBS loaded using four loading pins rather than two, therefore the loading pins can be made from materials with less creep resistance, this also allow the loading pin designer to design the loading pins using wide range of materials.

(ii). in the case of OBS the supporting material behind the loading pins, $\mathrm{k}$, can be made shorter than the $\mathrm{k}$ for the TBS, which mean the OBS. These two advantages of the OBS over the TBS, enable the OBS to be made from much smaller material samples shown in Figure 1.

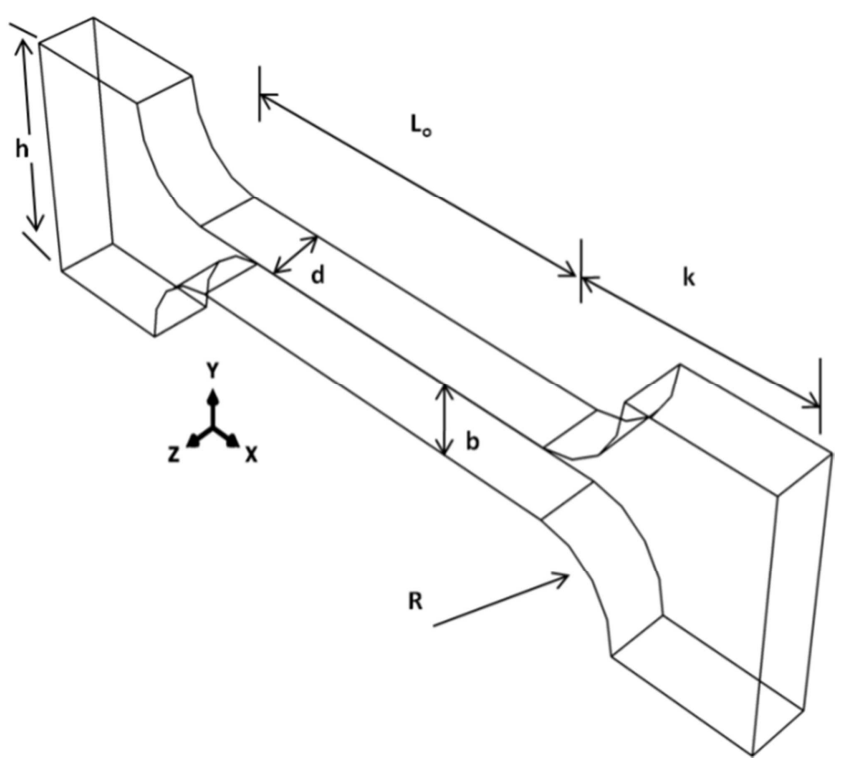

Figure 4. The Pin-loaded small one-bar specimen (OBS) shape and dimensions.

\subsection{Data Conversion Method for the OBS and the TBS.}

The creep data of the OBS and the TBS have to be converted to the corresponding uniaxial creep data. For this reason a conversion relationships have been obtained and used to convert the OBS and the TBS creep deformation (the load line displacement of the loading pin), to the corresponding uniaxial strain [11-14]; also to convert the applied load (the tensile load applied to the loading pin) to the corresponding uniaxial stress [11-14]. Finite element analysis is used to obtain the conversion relationships and the conversion factors which are used in the conversion relationships. The method which is used to obtain the conversion relationships and the conversion factors $\beta$ and $\eta$ have been detailed and published in [1114].

To determine stress level for the sup-siz uniaxial creep test specimen (see Figure 1), the applied load has to be divided by the cross section area of the specimen, i.e.,

$$
\sigma_{\text {nom }}=\frac{P}{A}
$$

Where $\sigma_{\text {nom }}$ is the nominal stress in the uniform part of the specimen, $\mathrm{P}$ is the applied load and $\mathrm{A}$ is the cross section area of the uniaxial specimen, i.e. $A=\pi r^{2}$. The creep strain, $\varepsilon^{c}$, for the sup-size uniaxial specimen can be calculated at any given time, by dividing the specimen extension by the original length, i.e.

$$
\varepsilon^{c}=\frac{L_{2}-L_{1}}{L_{1}}
$$

Where L1 and L2 are the specimen dimensions before and after testing. For the TBS and the OBS a Conversion factors $\beta$ and $\eta$ and conversion relationships i.e. Eqs (3-6) have to be used to determine the require loading and to convert the 
specimens despoilment to strain. The stress for the TBS can be calculated using Eq. (3a)

$$
\sigma_{\text {nom }}=\eta \frac{P}{2 b d}
$$

and for the OBS the stress can be calculated using Eq. (3b)

$$
\sigma_{\text {nom }}=\eta \frac{P}{b d}
$$

where $\sigma_{\text {nom }}$ is the nominal stress in the OBS and the TBS bars (equivalent uniaxial stress). $\eta$ is the stress conversion factor for the TBS and the OBS (the tool which is used to convert the applied load to the equivalent uniaxial stress), $\mathrm{P}$ is the applied load to the loading pins.

Eq. (5), has been used to convert the TBS and the OBS minimum creep deformation rates, measured between the centres of the loading pins, to the equivalent uniaxial minimum creep strain rates, i.e.

$$
\dot{\varepsilon}^{c}=\frac{\dot{\Delta}^{c}}{\beta L_{O}}
$$

where $\dot{\varepsilon}^{c}$ is the equivalent uniaxial minimum creep strain rate, $\dot{\Delta}^{c}$ is the TBS and the OBS minimum creep deformation rate, $L_{o}$ is the distance between the centres of the two loading pins and $\beta$ is the conversion factor. It is worth mentioning that the conversion factors $\beta$ and $\eta$ are specimen dimensions and geometry dependent therefore their numerical values change as the OBS and the TBS geometries change.

During the creep testing of the OBS and the TBS most of the specimens dimensions do not change significantly during the creep test [14] which mean the conversion factors $\beta$ and $\eta$ do not change significantly during the test. Therefore, the conversion relationship given by Eq. (5) can be rewritten as in Eq. (6)

$$
\varepsilon^{c}=\frac{\Delta^{c}}{\beta L_{o}}
$$

where $\varepsilon^{c}$ is the equivalent uniaxial creep strain for the OBS and the TBS, $\Delta^{c}$ is the OBS and the TBS creep deformation, $\beta$ is the reference stress parameter and $L_{o}$ is the length of the uniform bar for the OBS and the TBS. Therefore, Eq. (6) can be used to convert the entire creep curve for the OBS and the TBS [7].

\section{Specimens Modeling}

The FEA were carried out using the ABAQUS software package [19] for the specimens modelling. As the sup-size uniaxial specimen has a simple and axisymmetric shape, the Axisymmetric Elements have been used to model the specimen as shown in the Figure 5 (b). 3D-FE analyses were carried out for the OBS and the TBS using meshes which consist of 20-noded brick elements. Because of the nature of the study, it was necessary to model the entire specimens, as shown in Figures 5 (a and c). The boundary conditions, i.e. $u_{x}=0, u_{y}=0$ and $u_{z}=0$ was applied to the constraining side, through the loading pins in one side of the specimens. From the other side where the tensile loading were applied through the loading pins, the boundary conditions were, $\mathrm{u}_{\mathrm{Y}}=0$ and $\mathrm{u}_{\mathrm{z}}=0$. These boundary conditions also applied to the reference points in the central of the loading pins, which are assumed to be "rigid" in the FE model. For the TBS and the OBS Eqs. (3) and Eq. (4) are used consecutively to determine the required load, whereas, for the sup-size uniaxial specimen Eq. 1 is used to determine the loading.

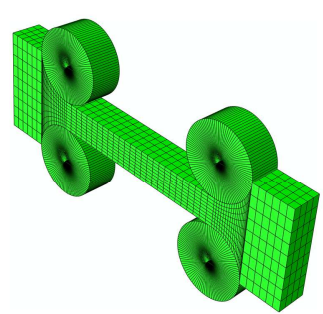

(a)

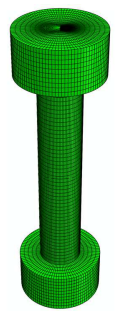

(b)

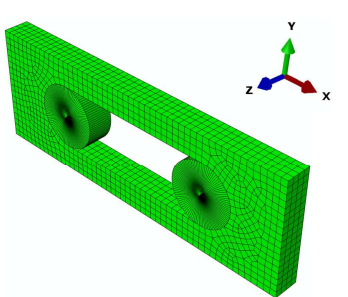

(c)
Figure 5. Finite element models and mesh for the TBS (a), the sup-size uniaxial specimen (b) and the TBS (c).

\section{Results and Investigation}

\subsection{The Affect of the Misalignment on the Specimens Minimum Strain Rate (MSR)}

Standard uniaxial creep test specimens where manufactured using the P91 steel which is one of that high temperature materials and used extensively in the high temperature applications; the specimens are all tested at $650^{\circ} \mathrm{C}$. The specimens are creep tested until failure at these stress levels of 70, 82, 87, 93 and $100 \mathrm{MPa}$ [12-14]. The finite element analyses for the sub-size uniaxial specimen and for the OBS and the TBS specimens were carried out using the $\mathrm{P} 91$ steel at $650^{\circ} \mathrm{C}$ [12-14]. The small specimens were constrained from one end and a tensile loading applied to the other end. The load applied to all specimens were calculated in order to generate stress levels of 70, 82, 87, 93 and $100 \mathrm{MPa}$ in the specimens (in the uniform straight part in the middle of the specimens). The creep minimum strain rates (MSRs) obtained from the FE analyses for all specimens with $(0.5,1,1.5 \mathrm{~mm})$ of misalignment and the corresponding uniaxial experimental test results are plotted together in Figures 6-8. It can be seen that very good agreement is found between all results. The FE results presented in the Figures 6-8 also indicate that the small misalignment $(0-1.5 \mathrm{~mm})$, between the two loading holders, have insignificant effect on the minimum strain rates (MSR) for the sub-size uniaxial creep test specimen and the OBS and the TBS creep test specimens. 


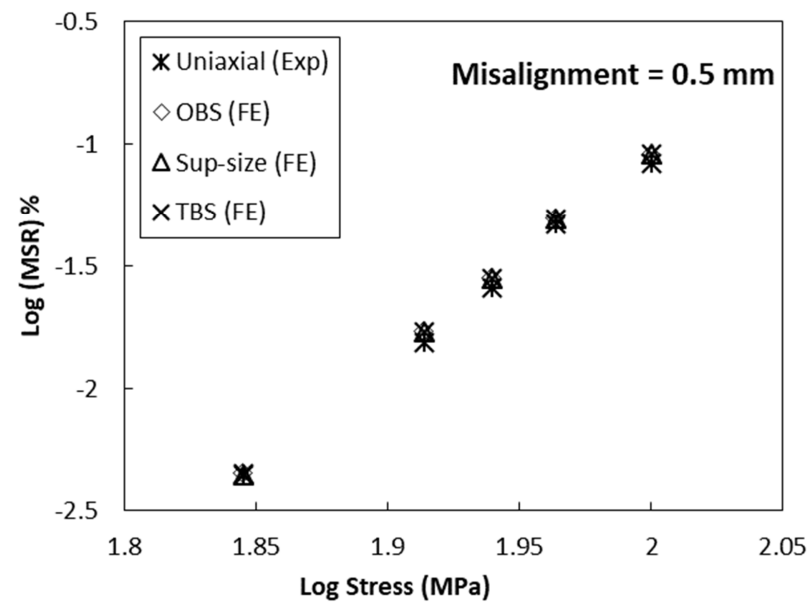

Figure 6. The creep minimum strain rates (MSRs) obtained from the FEA for the $O B S$, TBS and the sub-size uniaxial specimen with $0.5 \mathrm{~mm}$ misalignment, together with the corresponding experimental results obtained from the standard uniaxial creep test specimen for $P 91$ at $650^{\circ} \mathrm{C}$.

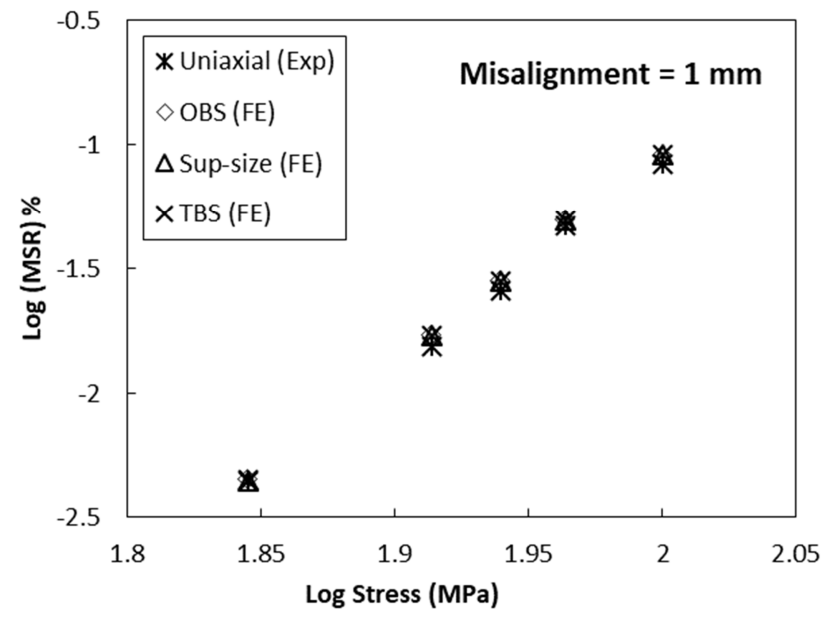

Figure 7. The creep minimum strain rates (MSRs) obtained from the FEA for the $O B S, T B S$ and the sub-size uniaxial specimen with $1 \mathrm{~mm}$ misalignment, together with the corresponding experimental results obtained from the standard uniaxial creep test specimen for $P 91$ at $650^{\circ} \mathrm{C}$.

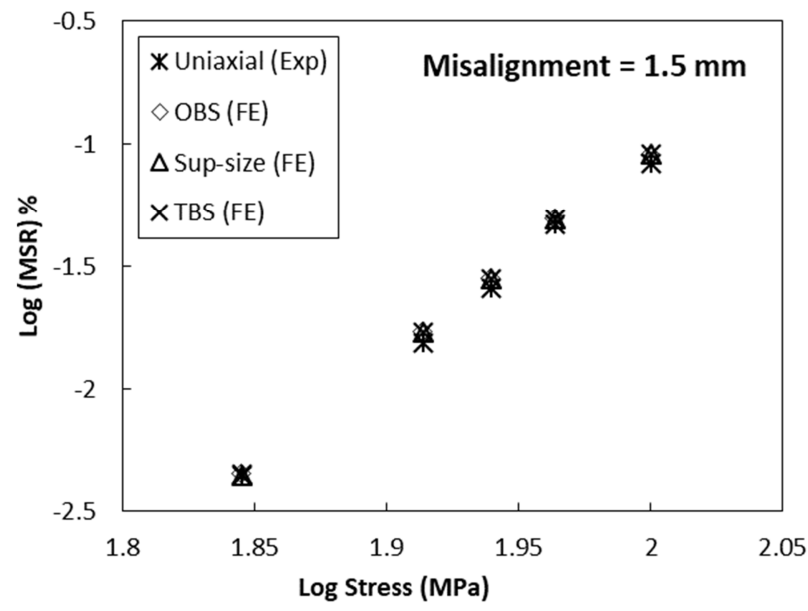

Figure 8. The creep minimum strain rates (MSRs) obtained from the FEA for the $O B S, T B S$ and the sub-size uniaxial specimen with $1.5 \mathrm{~mm}$ misalignment, together with the corresponding experimental results obtained from the standard uniaxial creep test specimen for P91 at $650^{\circ} \mathrm{C}$.

\subsection{The Effect of the Misalignment on the Specimen's Failure Times $\left(T_{F}\right)$}

In this stage of investigation, the FE analyses were performed using the Liu-Murakami creep damage model, instead of Norton's model to obtain a full creep strain-time curves [7, 13]. The P91 steel material creep constants at $650^{\circ} \mathrm{C}$ were used in the FE analyses [7]. The creep constants for this material at this temperature were published also in [13]. The stress level were constant at $70 \mathrm{MPa}$ for all the analyses. The analyses were performed several times for all specimen types, with different degree of misalignment, i.e. $(0.50,1.00,1.50$ and $2 \mathrm{~mm})$. These values of misalignments were choosing because it is unlikely in today's modern manufacturing and assembling technology to find misalignment in the testing and manufacturing machines that will exceed these levels. The FE failure times for all specimens are compared in Figure 9. The failure times of the TBS and OBS is insensitive to this range of misalignment values as they always fail at $1004 \mathrm{~h}$. This is because the OBS and the TBS have a flexible loading fixture during loading, i.e, it can rotate during loading to achieve self-alignment. However, for the sub-size uniaxial specimen the failure times is inversely proportional to the misalignment values as it can be seen from Figure 9.

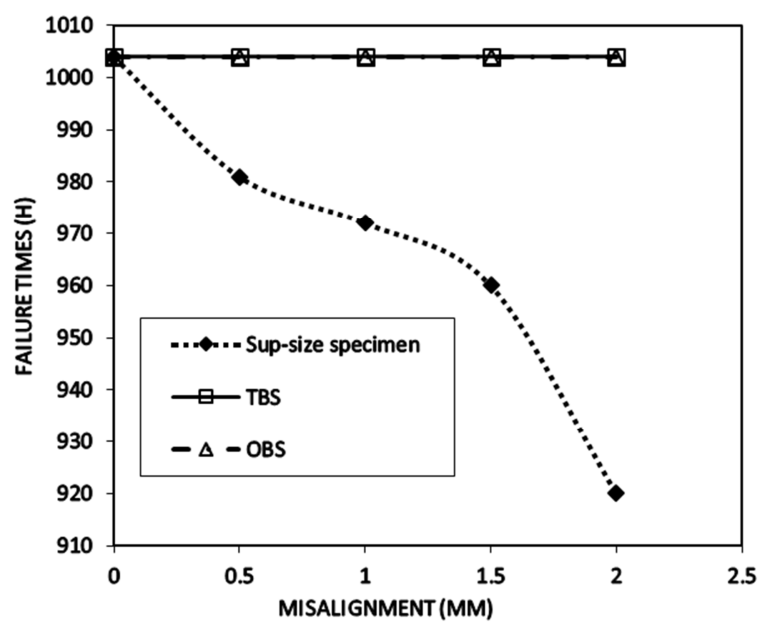

Figure 9. Shows the effect of misalignment on the failure times obtained from the FE analyses for the sub-size uniaxial specimen, OBS and the TBS, for $\mathrm{P} 91$ steel at $70 \mathrm{MPa}$ and $650^{\circ} \mathrm{C}$.

\section{Conclusions}

It is well known fact that the misalignment during tensile creep testing using uniaxial specimens has negative effects on the test accuracy. However. There isn't any study previously has been conducted to study the effects of the misalignment on creep test results using the pin loaded creep test specimens. This study has approved that the loading misalignment during the tensile creep testing of the OBS, the TBS also the Sup-size uniaxial creep test specimens, has negligible effect on the creep minimum strain rate (MSR) in the range of misalignment between $0-2 \mathrm{~mm}$. However, there is significant effect on the 
Sup-size uniaxial creep test specimens failure time as result of the misalignment in the range of $0-2 \mathrm{~mm}$, during the creep testing. This misalignment lead to a premature failure for the specimen and the premature failure is proportional the misalignment level. On the other hand, the misalignment during creep testing has no effect on the failure time of the OBS and the TBS. This is because the OBS and the TBS has the advantage of the self-aligning during loading. The results presented in this paper indicate that the pin loaded small creep test specimens I.e., the OBS and TBS, should be used instead of the sup-size uniaxial specimen, when it is possible. This is to eliminate the effect of the possible misalignment during tensile creep loading on the specimens failure time, which will ensure accurate creep assessment.

\section{References}

[1] Hao S., Yang H., Elsworth D. (2017). An accelerating precursor to predict time-to-failure in creep and volcanic eruptions. Journal of Volcanology and Geothermal Research, 3431, 252-262. doi: 10.1016/j.jvolgeores.2017.07.009.

[2] Song M., Xu T., Y. Keyi, Yu H., Sun C. (2019), Creep failure of a steam pipe girth weld and NDT strategy on creep damage, Journal of Engineering Failure Analysis, 104, 673-681. doi: 10.1016/j.engfailanal.2019.06.048.

[3] Hyo-Jin K. (2005). Assessment of creep life fraction for inservice high-temperature components, Journal of Engineering Failure Analysis, 12 (4) 578-585. doi: 10.1016/j.engfailanal.2004.09.00.

[4] Piotrowski L., Chmielewski M., Golański G., Wieczorek P. (2019). Analysis of the possibility of creep damage detection in T24 heat resistant steel with the help of magnetic nondestestructive testing methods, Engineering Failure Analysis. 102, 384-394. doi: 10.1016/j.engfailanal.2019.04.054.

[5] Shlyannikov V., Tumanov A., Boychenko N. (2018). Creepfatigue crack growth rate assessment using ductility damage model, International Journal of Fatigue, 116, 448-461. doi: 10.1016/j.ijfatigue.2018.07.003.

[6] Pasquale G., Filippo B., Grzegorz G. (2016). Analysis of creep stresses and strains around sharp and blunt V-notches, Theoretical and Applied Fracture Mechanics. 85, 435-446. Doi: 10.1016/j.tafmec.2016.06.003.

[7] Ali B. (2015). The Pin-Loaded Small One-Bar Specimen in Use to Determine Uniaxial and Multiaxial Creep Data, High. Temp. Mater. Proc., 34 (6), 563-572. Doi: 10.1515/htmp2015-0029.

[8] Liu Y. J., Zhao B., Xu B., Yue Z. (2007). Experimental and numerical study of the method to determine the creep parameters from the indentation creep testing, Materials Science and Engineering: A, 456, 103-108. Doi: 10.1016/j.msea.2006.11.098.

[9] Evans M., Wang D. (2008). The small punch creep test: some results from a numerical... J Strain Anal Eng Des 45 (3): 141164. doi: 10.1243/03093247JSA592 43.

[10] Hidenari T., Masami F. (2014). Set of conversion coefficients for extracting uniaxial creep data from pseudo-steady indentation creep test results, Materials Science and Engineering: A. 602, 98-104. Doi: 10.1016/j.msea.2014.02.060.

[11] Ali B., Tom H., Sun W. (2016). Small Two-Bar Specimen Creep Testing of Grade P91 Steel at $650^{\circ} \mathrm{C}$. High Temperature Materials and Processes 35 (3): 243-252. DOI: 10.1515/htmp2014-0188.

[12] Tom H., Ali B., Sun W. (2013). Analysis and Design of a Small, Two-Bar Creep Test Specimen, Journal of Engineering Materials and Technology. 135 (4): 100-109. Doi: $10.1115 / 1.4025192$.

[13] Tom H., Ali B., Sun W. (2014). On the Determination of Material Creep Constants Using Miniature Creep Test Specimens, Journal of Engineering Materials and Technology, 136 (2): 1006-1016. doi: 10.1115/1.4026596.

[14] Ali B. (2014). Development of non-destructive small specimen creep testing techniques. $\mathrm{PhD}$ thesis, The University of Nottingham. DOI: 10.13140/RG.2.1.3286.3203.

[15] Garzillo A., Guardamagna C., Moscotti L., Ranzani L. (1996). A technique for the residual life assessment of high temperature components based on creep-rupture testing on welded miniature specimens. International Journal of Pressure Vessels and Piping. 66 (1-3) 223-232. Doi: 10.1016/03080161(95)00097-6.

[16] Ganesh K. J., Laha K. (2017). Localized creep characterization of $316 \mathrm{LN}$ stainless steel weld joint using Small Punch Creep test, Materials Science and Engineering: A. 705, 72-78. Doi: 10.1016/j.msea.2017.08.062.

[17] Prasanna H., Rajendra K., Udupa U.(2016). Indentation creep studies to evaluate the mechanical properties of stainless steel, Australian Journal of Mechanical Engineering, 14 (1), 39-43. Doi: 10.1080/14484846.2015.1093214.

[18] Andrésa D., Lorenzob M., Lacallea R., lvareza J, Alegrec J. (2016). Application of the Small Punch Creep test to predict times to rupture on magnesium alloys, Theoretical and Applied Fracture Mechanics Part A, 86, 45-50. doi: 10.1016/j.tafmec.2016.08.004.

[19] ABAQUS, 6.11-3 Standard User Manual, ABAQUS, Inc, USA, 2010. 